\title{
Scenario Simulation Model of the Production, Transportation and Asphalt Paving
}

\author{
Mario Galić \\ J.J. Strossmayer University \\ of Osijek, Faculty of Civil \\ Engineering Osijek, \\ mgalic@gfos.hr
}

\author{
Ivica Završki \\ University of Zagreb, \\ Faculty of Civil \\ Engineering, \\ zavrski@grad.hr
}

\author{
Zlata Dolaček-Alduk \\ J.J. Strossmayer University \\ of Osijek, Faculty of Civil \\ Engineering Osijek, \\ zlatad@gfos.hr
}

DOI 10.5592/otmcj.2015.3.1

Research paper

\section{Keywords}

Asphalt; Paving; Process

Chain; Production;

Scenario; Simulation;

Transportation
ORGANIZATIONAL PROCESSES MODELLING AND SCENARIO SIMULATION IS PROVED TO BE AN EFFICIENT TOOL FOR THE QUANTITATIVE STRENGTHENING OF THE DECISION MAKING PROCESS. In business of production, transportation and paving of great quantities of asphalt mixture, solving problem of project's fragmented sub-processes has been emphasized by previous researchers as a high priority. Detached process modeling and optimization without taking into account constraints of interrelations among sub-processes cannot offer the optimal or quality solution. Thus, it is necessary to structure a developing and easily adjustable model which will be able to integrate all sub-processes with their interrelations. In this paper authors gave a review of the findings and recommendations of the previous researches. Based on the recommendations, authors structured a developing simulation model for planning and optimization "just in time" chain of processes of production, transportation and paving of great quantities of asphalt mixture. Suggested model is based on the algorithm for scenario simulations which is dynamic and adjustable for changes and updates of the input parameters. 


\section{INTRODUCTION}

The specificities of construction projects are repercussion of their stochastic and dynamic environment, as well as their common repetitive operations. Choice of applicable planning and controlling methods directly depend on this fact, as well as the optimization methods and tools in the continuous process of planning in project's life cycle. The flow of information in the project is of high importance for optimization, therefore it is crucial to define which of the modelling, simulation and optimization methods are most suitable for certain problems in certain phases of planning. Trends of recently developed methodologies, in processes modelling and simulation, are mainly focused on incorporation of the production and environment constraints, as well as the interpretation of the interaction and dependences among system's main components. The aforementioned trends are reflected in the need and application of such tools for processes optimization in large-scale projects where quantified explanation of the decisions is most needed. Engineers have been facing problems of finding the quantitative confirmation of the plans for large scale asphalt paving projects. By the usage of common mathematical method, in literature known as transportation problem (TP), it is highly questionable and risky to declare the suggested solution (i.e. program) as optimal. There are two main reasons for that, underlined by the authors (Galić et al., 2013a):

One objective function (i.e. minimization of the total transportation costs) without taking into account all significant integral processes.

Balanced model which assumes that offer has to match demand, practically meaning that all the appointed sources will be involved in the programme.

Till now planning the asphalt paving projects was concentrated on planning the efficiency of the paving operations, while asphalt mixture, plants capacities and reliabilities, as well as the transportation means, have been taken as already fulfilled assumptions. In order to ensure optimal and continuous work, but also the quality of the final product, it is crucial to include the complete chain of processes with belonging assumptions: production, transportation and paving. This fact was elaborated by authors (Zhang et al., 2013) and hypothesize that it will not be crucial only for the paving process efficiency, but for the production as well.

In this paper authors give a literature review and suggest a simulation model which involves all of the subprocesses in the chain of processes in hot mixture of asphalt (HMA) production, transportation and paving. Suggested model is called developing model because of its ability for adjustments to constant changes of input parameters, which are common in all of the mentioned processes in chain, and regarding the quality of input parameters through project's life cycle phases (conception $\rightarrow$ realization).

\section{Estimated input parameters}

\section{Literature review}

Computational modelling of the organizational processes as a developing scope of methodologies for making, monitoring and optimization of the project plans various researchers worldwide (Wynn et al., 2013; Corona-Suárez et al., 2014; Beloglazov et al., 2015; Galić et al., 2013b) recommend as an excellent reengineering of the construction industry. Optimization methods of linear and non-linear programming have been neglected for many years, since their expansion in 1970's when mathematical (theoretical) models were developed. The main reason why those methods have been neglected authors (Márquez, 2010; Kall and Mayer, 2005; AbouRizk et al., 2011; Hsie et al., 2009) have identified in rather complex application for modelling and optimization of stochastic processes, which are common for construction.

With today's developed state of the IT sector complexity and issues of the mentioned methods aren't critical. Optimal solutions are gained in short
A1

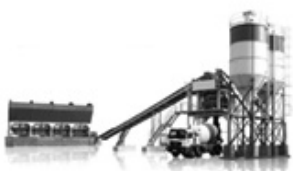

a1

A2

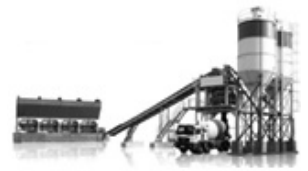

a2

An

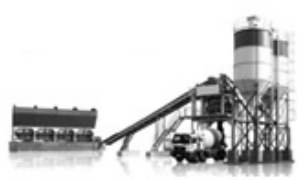

an

Total supply $\Sigma$ ai
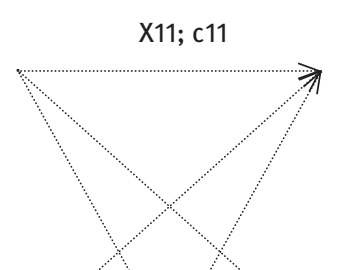

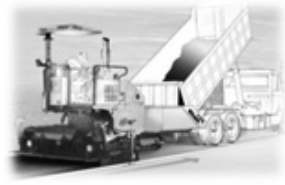

b1

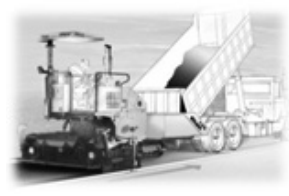

b2

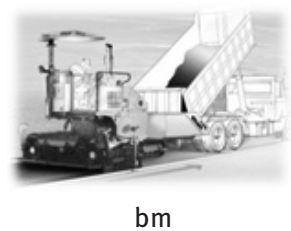

$\mathrm{bm}$

Figure 1: Graphical definition of the TP network material flow model (Galić et al., 2015) 


\begin{tabular}{|c|c|}
\hline Author(s) & Type of TP \\
\hline $\begin{array}{l}\text { Klanšek and } \\
\text { Pšunder, } 2010\end{array}$ & $\begin{array}{l}\text { Non-linear TP - } \\
\text { when expenses are } \\
\text { nonlinear in relation } \\
\text { to the unit of the } \\
\text { transported good. }\end{array}$ \\
\hline $\begin{array}{c}\text { Babazadeh et al., } \\
2011\end{array}$ & $\begin{array}{l}\text { Combination of } \\
\text { the TP and routing } \\
\text { problem, with the } \\
\text { objective function: } \\
\text { minimization of the } \\
\text { travel time. }\end{array}$ \\
\hline $\begin{array}{l}\text { Hussain and } \\
\text { Kumar, } 2012\end{array}$ & $\begin{array}{l}\text { Fuzzy TP - case of } \\
\text { undetermined or } \\
\text { uncertain sources } \\
\text { and sinks. }\end{array}$ \\
\hline Klanšek, 2014 & $\begin{array}{l}\text { Non-linear mixed- } \\
\text { integer discrete TP. }\end{array}$ \\
\hline Bai and Yao, 2014 & $\begin{array}{l}\text { TP in crisis situations } \\
\text { with dynamic } \\
\text { constraints. }\end{array}$ \\
\hline Guo et al., 2015 & $\begin{array}{l}\text { TP with unknown } \\
\text { costs and sources. }\end{array}$ \\
\hline $\begin{array}{c}\text { Damci-Kurt et al., } \\
2015\end{array}$ & $\begin{array}{l}\text { TP with constrained } \\
\text { source capacities } \\
\text { with optional sources } \\
\text { to supply. }\end{array}$ \\
\hline $\begin{array}{l}\text { de França Aguiar } \\
\text { et al., } 2015\end{array}$ & $\begin{array}{c}\text { Original form of the } \\
\text { TP. }\end{array}$ \\
\hline
\end{tabular}

Method(s) and models applied
Authors have applied three methods
(models) for solving such problems.
Applied methods are based on the branch
methods (global optimization).

Metaheuristic method based on the particle swarm optimization (PSO) with comparison with the ant colony optimization (ACO) model.

Authors applied methods known as intuited zero method, by which they have sized the area of feasible solutions.

Author compared three known methods for solving mixed-integer nonlinear programming (MINLP) - i.e. branch and reduce method, branch and cut method, combination of the global and local search strategies

Mathematical model with associated variables by which the dynamic constraints are controlled.

Iterative method of inclusion of objective function values and intervals of constraints.

Mixed-integer nonlinear programming.

Authors suggested a new method of maximal offer and minimal expenses, with the belonging optimization algorithm.

\section{Conclusions}

All three applied methods have provided correct and similar results in relatively shorter period than previous methods.

Authors proved that PSO method is more successful in terms of time/effort needed for structuring the model and results presentation.

Method was proven successful for simple problems, while for problems of more complexed nature it has to be modified and verified.

All three applied methods have provided satisfactory results and in acceptable time. In terms of their comparison author stated that none of them have showed significant advantage.

Suggested model is still theoretical and has to be verified.

Applied method has transferred the problem into a scenarios of original TP.

Method is applicable for addressed TP and it is still to be verified.

Method has been proven as an improvement in term of simplification of the calculation and for gaining the initial result. In further work authors are developing software based on the suggested algorithm.

\section{Table 1: State of the art of methods, models and algorithms for solving TPs}

period of time and what is very important: gained results are surely optimal meaning that they are ensured from the sub-optimality which is common for mathematical models earlier mentioned. Thus, modelling and optimization is once again in the focus of scientist researching the problems of organization, planning, control and optimization of the construction processes and production.

Transportation problem (TP) is just one of the methods and models which are under the scope and which application is being expanded and modified (shown in figure 1). The main problem of the TP was complex application for large matrix forms. Nowadays, simulation models have been proved not just as efficient in solving large problem of TP, but as well as a visualization tool of the material flow, resource allocation, bottlenecks detection and prevention, and various scenarios simulation (i.e. what-if scenarios) noted by authors (AbouRizk, 2010; Mariz et al., 2013; Tang et al., 2014). However, authors (Tang et al., 2014) have underlined that available simulation software often tends to have complicated input and export of the data, and suggests that further researchers should detect alternative software and work on more general approach of processes modelling in order to be more understandable and user-friendly.

For TP there are various deterministic, heuristic and metaheuristic algorithms which are more or less effective (depending on the type of the problem). Due to the diversity of optimization problems, methods and tools authors made a review of those concerning the optimization of construction production in past 5 years (Table 1). 
Although, aforementioned methods and algorithms are primarily developed for solving and optimization the transportation of the goods (denoted in Figure 1 as " $X_{i j}$ ") from sources (denoted in Figure 1 as " $A_{1} \rightarrow n$ " with belonging capacities " $\mathrm{a}_{1 \rightarrow \mathrm{n}}$ ") to sinks (in Figure 1 denoted as " $B_{1} \rightarrow m$ " with belonging demand " $b_{1} \rightarrow m$ "), they can be modified for purpose of simulation and optimization of the expanded models including other integral processes and constraints, but in the domain of TP according to (Galić et al., 2013a).

According to the recommendations for further researchers suggested by the authors (Nassar et al., 2003; Peyret and Tasky, 2004) simulation software should allow user to model the mentioned chain of processes (i.e. asphalt mixture production, transportation and paving) as a holistic processes and optimize it taking into account interrelated constraints of integral subprocesses. This approach of modelling and simulation will offer final optimal solution and reduce the risk of suboptimal results.

\section{Process chain simulation model of production, trans- portation and asphalt paving}

\section{Description of the model}

Optimization of the complete chain of processes has a form of expanded TP which has two sides of constraints (beside TP's belonging transportation constraints): on one side there are constraints of the production and on the other there are constraints of the asphalt paving operations (shown in Figure 1). The main characteristics or assumptions of the problem which have to be fulfilled are:

> Construction sites are demanding large quantities of the asphalt mixture in short time period.

> Storage of the asphalt mixture is not an option (production and paving "just in time").

$\checkmark$ There is a significant difference between efficiency among processes in chain.

Dynamic (stochastic) environment and influences on the project.

According to the mentioned assumptions, sources (asphalt plants) have to be defined by their capacities, availabilities and reliabilities for both (i.e. capacity and availability). As it was mentioned earlier authors propose a model which has to be developing and adaptable to changes in the project. Therefore, in early project's phase capacity could be estimated by the given plants nominal capacity, while availability of the potential plants depends on the plants schedule but more importantly on the mixture which is required and the distance of the plant from the given site locations.

The type of asphalts mixture is given and it is analyzed through its quality requirement which is indicated by its temperature. The temperature is decreasing from the point of production and loading into the transportation vehicle, to the point of paving. Therefore, the distance between asphalt plant and construction site is defined by the allowed temperature drop. For HMA the production temperature is in the interval of $160^{\circ}-180^{\circ} \mathrm{C}$, while required temperature of paving is in the interval of $110^{\circ}-135^{\circ} \mathrm{C}$ elaborated by the authors (Roberts et al., 2003; Wang et al., 2014; Miller et al., 2011).

\section{Sensitivity of the model}

Asphalt plants as sources are critical processes in the chain. In comparison to other sub-processes in the chain they are not easily replaceable without influencing the entire project and optimal program. Thus, plants reliability is significant factor for project planning, program's post-optimal analysis and scenario evaluation. Each source (plant) engaged in the optimal program has to be quantitatively evaluated through its reliability for fulfilling the demand gained by the optimal program.

\section{Mathematical interpretation}

of the model

The mathematical model of original TP (objective function equation 1 and belonging constraints equation 2) has been taken as a starting point for the model modification (i.e. by adding the constraints (dependences) among components).

$$
\begin{aligned}
& \min Z=\sum_{j=1}^{n} \sum_{i=1}^{m} c_{i j} * x_{i j} \\
& \sum_{j=1}^{n} x_{i j}=a_{i} ; \sum_{i=1}^{m} x_{i j}=b_{j} ; x_{i j} \geq 0
\end{aligned}
$$

First and the most important is the dependence of distances between the plants and construction sites " $\mathrm{L}_{\mathrm{mn}}$ " on temperature drop " $\Delta \mathrm{t}$ " during the transportation (Equation 3) for the HMA. This dependence is actually a physical constraint of the model. The potential asphalt plants are those in the circle in which the time of the HMA transportation will not influence the determined temperature for paving $\left(110^{\circ}-135^{\circ} \mathrm{C}\right)$.

$\mathrm{L}_{\mathrm{mn}}(\Delta \mathrm{t}) \leq 70-80 \mathrm{~km} ; \Delta \mathrm{t} \leq 50-70^{\circ} \mathrm{C}$

The second dependence is the influence of the construction site on paving operations efficiency " $E_{R P}$ " " (i.e. rollers and asphalt pavers) on the transportation " $\mathrm{E}_{\mathrm{T}}$ " and production of asphalt mixture " $E_{p}{ }^{m}$ " (Equation 4). By this the model will appreciate site's efficiency and adapt production and transportation efficiency to matching.

$$
\Sigma \mathrm{E}_{\mathrm{RP}}^{\mathrm{n}} \rightarrow \Sigma \mathrm{E}_{\mathrm{T}} \rightarrow \Sigma \mathrm{E}_{\mathrm{P}}^{\mathrm{m}}
$$

The last dependence, but not the least, is the reliability factor " $R$ " of each plant based on its nominal capacity which will be a part of the researchers' further work based on the following mathematical expression for estimation of the reliability of technical systems given by authors (Barlow, 1998, Birolini, 1997) (Equation 5): 
$R(t)=\sum_{i=k}^{n}\left(\begin{array}{l}n \\ i\end{array}\right)\left[1-F_{i}(t)\right]^{i}\left[F_{i}(t)\right]^{n-1} ; t=\frac{x_{m}}{E_{p}^{m}}(5)$

The given equation 5 is used for analysis of semi serial processes with " $k$ " elements $(k>1)$ where number " $n$ " is the number of required operable elements for the systems fully capacity and " $F_{i}(t)$ " is the function of failure in time " $t$ " which depends on the amount of asphalt " $X_{m}$ " from the asphalt plant " $m$ " gained by the simulation (optimization) and its production efficiency “ $E_{p}{ }^{m}$ ”.

\section{Algorithm}

The first step of the model structuring is data collecting and forming the input data file (data about plants: number, capacities, locations, reliabilities regarding the capacities; transportation means: their number, capacities, distances from plants to the sites; construction sites: their number, locations, needed quantities of HMA, paving technology and its efficiency). After that it is possible to structure the computational model in simulation software and to setup the scenario simulations.

In processes of setting up the simulation time it is necessary to connect the input parameters to the models entities in the simulation software. Third step is to run the simulations and to export the results into the file (different place) of the input parameters for further analysis. The result of the simulation will provide one optimal solution (program) and given number of scenarios with belonging programs. The fourth step is the post optimal analysis on the basis of risk assessment of the plants reliabilities engaged in the program (Figure 2). Risk assessment through the plants reliability in the optimal programme is significant for post optimal analysis and evaluation of the possible scenarios. Each of the sources has to be quantitatively evaluated by its reliability factor for accomplishing the requirement of demand for that quantity and production time. As it is shown in Figure 2 and in Table 2 the user has to make final decision about the total risk of the optimal program and possible scenarios, and make a decision either to go back to the models input parameters and setup a new simulation set or accept one of the given scenarios with the total risk defined.

\begin{tabular}{|c|c|c|c|}
\hline & $\begin{array}{c}\text { Total } \\
\text { costs }\end{array}$ & $\begin{array}{c}\text { Total } \\
\text { duration }\end{array}$ & $\begin{array}{c}\text { Risk } \\
\text { assess- } \\
\text { ment }\end{array}$ \\
\hline $\begin{array}{c}\text { Optimal } \\
\text { program }\end{array}$ & C & D & R \\
\hline Scenario 1 & C1 & D1 & R1 \\
\hline Scenario 2 & C2 & D2 & R2 \\
\hline Scenario 3 & C3 & D3 & R3 \\
\hline Scenario N & CN & DN & RN \\
\hline
\end{tabular}

Table 2: Matrix form of the post

optimal analysis for the decision making gained by simulation

\section{Conclusions and plans for further research}

Process modelling and scenario simulations in construction industry are becoming more important. Scenario simulation is becoming vital tool for decision making through the entire project's life cycle. Thus, crucial requirement put before models is their incorporation and acknowledgment of the projects stochastic and dynamic environment. The difference between static and dynamic model lies

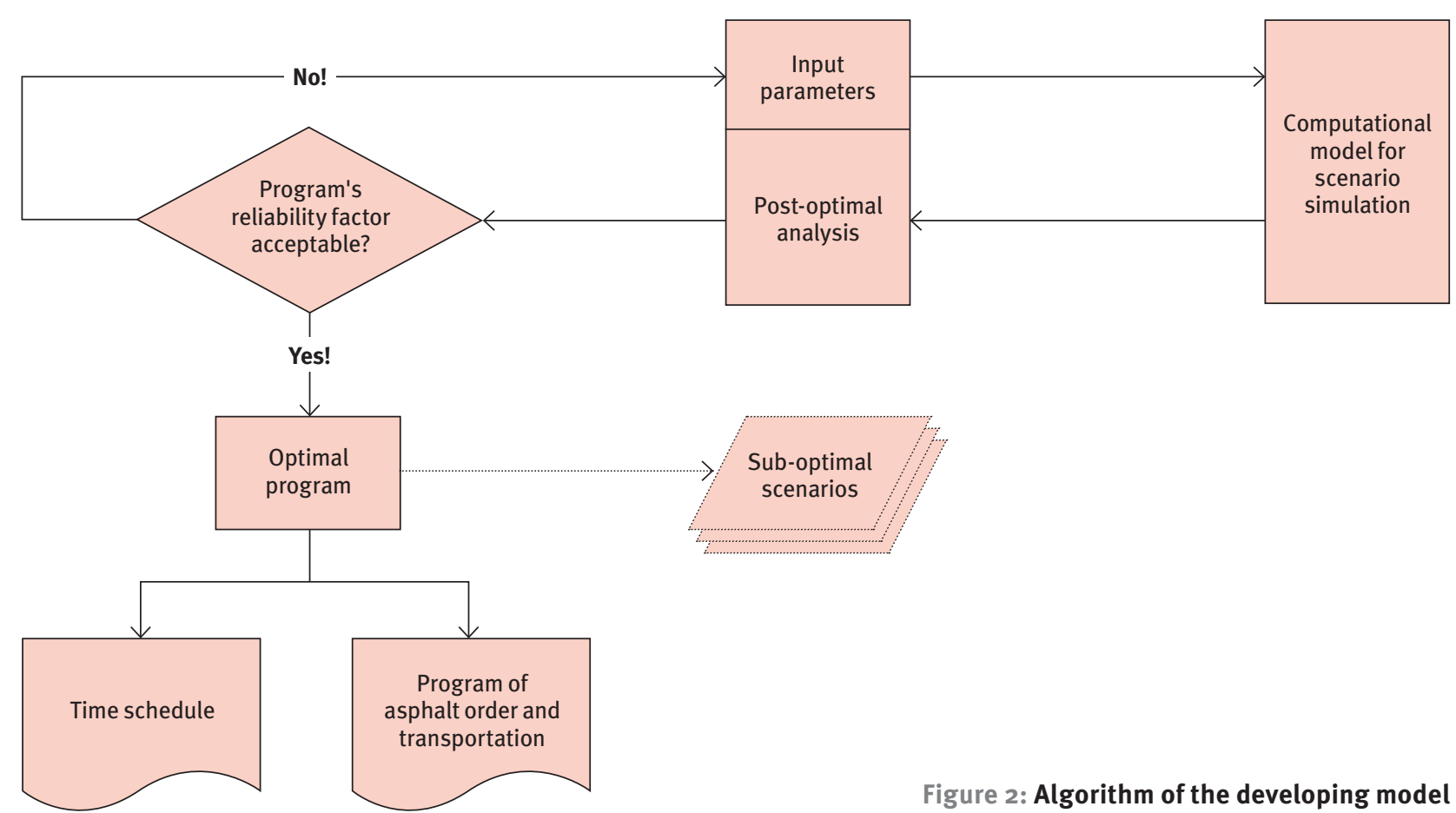


in its ability to adapt itself to constant changes of input parameters and their priority. So, it is logical that sensitive spot of the modelling and simulation is input parameters. Suggested developing model allows the user easy and secure update of the input parameters regarding to their constant change (change of their presence, priority and quality). Input parameters data file (location of sources and sites) in author's plan for future research will be connection to internet databases (e.g. GPS maps for locations and routes for transportation; weather forecast, etc.) for making a step closer to the realtime simulations. With this improvement control of the input parameters is done in one place outside of the models interface in a connected file, keeping in mind that the input parameters for the model are usually collected and therefore the input parameters data file has to be in a compatible format to the data base oriented software (e.g. Microsoft Excel or Access). This will enhance the communication among the participants in projects. Concept of the suggested developing model is similar to the Building Information Modelling concept (BIM). While BIM has already a firm point of application in public highway construction projects worldwide, concept of processes simulation still hasn't. The logical connection of the two modelling and simulation concept is something what future improvement should tend by firstly bridging their different orientations. The final goal of establishing the bidirectional connection between them is their synergy for the ultimate simulation tool in planning and optimization the chain of processes of production, transportation and asphalt paving projects.

\section{References}

Abourizk, S. (2010), "Role of simulation in construction engineering and management”, Journal of Construction Engineering and Management, Vol. 136, No 10, pp. 1140-1153

Abourizk, S., Halpin, D., Mohamed, Y. \& Hermann, U. (2011), "Research in modeling and simulation for improving construction engineering operations", Journal of Construction Engineering and Management, Vol. 137, No 10, pp. 843-852

Babazadeh, A., Poorzahedy, H. \& Nikoosokhan, S. (2011), "Application of particle swarm optimization to transportation network design problem", Journal of King Saud University-Science, Vol. 23, No 3, pp. 293-300

Bai, G.-Z. \& Yao, L.-N. "Grey Bottleneck Transportation Problems”, in Cao, B.-Y. \& Nasseri, H. (Ed.), Springer, pp. 357-364

Barlow, R. E. (1998), Engineering reliability, Siam, Berkeley, California

Beloglazov, A., Banerjee, D., Hartman, A. \& Buyya, R. (2015), “Improving Productivity in Design and Development of Information Technology (IT) Service Delivery Simulation Models", Journal of Service Research, Vol. 18, No 1, pp. 75-89

Birolini, A. (1997), Quality and Reliability of Technical Systems: Theory, Practice, Management, Springer, Berlin

Corona-Suárez, G. A., Abourizk, S. M. \& Karapetrovic, S. (2014), "Simulation-Based Fuzzy Logic Approach to Assessing the Effect of Project Quality Management on Construction Performance”, Journal of Quality and Reliability Engineering, Vol. 2014, No 1, pp. 1-18

Damc1-Kurt, P., Dey, S. S. \& Küçükyavuz, S. (2015), "On the transportation problem with market choice”, Discrete Applied Mathematics, Vol. 181, No 1, pp. 54-77

De França Aguiar, G., Aguiar, B. D. C. X. C. \& Wilhelm, V. E. (2015), "The MOMC Method: a New Methodology to Find Initial Solution for Transportation Problems", Applied mathematical sciences, Vol. 9, No 19, pp. 901-914

Galić, M., Dolaček-Alduk, Z. \& Završki, I. “The importance of additional criteria in solving transportation problem", in Hajdu, M. \& Skibnievski, M. M. (Ed.), Proceedings Creative Construction Conference 2013, Diamond Congress, Ltd, pp. 219- 229

Galić, M., Završki, I. \& Dolaček-Alduk, Z. "Reengineering the construction companies in time of the recession”, in Dunović, I. B., Mlinarić, V. \& Završki, I. (Ed.), Proceedings, pp. 68-78

Galić, M., Završki, I. \& Dolaček-Alduk, Z. “Process Chain Simulation Model of Production, Transportation and Asphalt Paving “, in Cerić,
A., Korytarova, J., Radujković, M., Vukomanović, M. \& Završki, I. (Ed.), Conference Proceedings, Croatian Association for Construction Management ; University of Zagreb, Faculty of Civil Engineering pp. 155-162

Guo, H., Wang, X. \& Zhou, S. (2015), “A Transportation Problem with Uncertain Costs and Random Supplies", International Journal of e-Navigation and Maritime Economy, Vol. 2, No 1, pp. 1-11

Hsie, M., Chang, C.-J., Yang, I.-T. \& Huang, C.-Y. (2009), "Resource-constrained scheduling for continuous repetitive projects with time-based production units", Automation in Construction, Vol. 18, No 7, pp. 942-949

Hussain, R. J. \& Kumar, P. S. (2012), “Algorithmic approach for solving intuitionistic fuzzy transportation problem", Applied mathematical sciences, Vol. 6, No 80, pp. 3981-3989

Kall, P. \& Mayer, J. (2005), Stochastic linear programming: Models, Theory, And Computation, Springer, Zurich

Klanšek, U. (2014), “Solving the nonlinear discrete transportation problem by MINLP optimization”, Transport, Vol. 29, No 1, pp. 1-11

Klanšek, U. \& Pšunder, M. (2010), “Solving the nonlinear transportation problem by global optimization”, Transport, Vol. 25, No 3, pp. 314-324

Mariz, R. N., Picchi, F. A., Granja, A. D. \& De Melo, R. S. S. (2013), "Production Cells in Construction: Considering Time, Space and Information Linkages to Seek Broader Implementations", Journal of Engineering, Project, and Production Management, Vol. 3, No 1, pp. 46-46

Márquez, A. C. (2010), Dynamic modelling for supply chain management: dealing with frontend, back-end and integration issues, Springer Science \& Business Media, London

Miller, S., Hartmann, T. \& Dorée, A. (2011), "Measuring and visualizing hot mix asphalt concrete paving operations", Automation in Construction, Vol. 20, No 4, pp. 474-481

Nassar, K., Thabet, W. \& Beliveau, Y. (2003), "Simulation of asphalt paving operations under lane closure conditions", Automation in Construction, Vol. 12, No 5, pp. 527-541

Peyret, F. \& Tasky, R. (2004), “A traceability system between plant and work site for asphalt pavements", Computer-Aided Civil and Infrastructure Engineering, Vol. 19, No 1, pp. 54-63

Roberts, F., Kandahl, P., Brown, E., Lee, D. \& Kenedy, T. (2003), Vruće asfaltne mješavine - Materijali, projektiranje i ugradnja, Zagreb

Tang, Y., Liu, R. \& Sun, Q. (2014), “Schedule control model for linear projects based on linear scheduling method and constraint programming", 
Automation in Construction, Vol. 37, No pp. 22-37 Wang, Y., Zhu, S. \& Wong, A. S. (2014), “Cooling time estimation of newly placed hot-mix asphalt pavement in different weather conditions", Journal of Construction Engineering and Management, Vol. 140, No 5, pp.1-11

Wynn, M. T., Ouyang, C., Low, W. Z., Kanjanabootra, S., Harfield, T. \& Kenley, R. (2013), “A process-oriented approach to supporting Offsite Manufacture in construction projects", (Ed.), International Council for Research and Innovation in Building and Construction (CIB), pp. 1-14

Zhang, M., Heitzman, M. \& Smith, A. E. (2013), “Improving Hot Mix Asphalt Production Using Computer Simulation and Real Time Optimization", Journal of Computing in Civil Engineering, Vol. 28, No 3, pp. 1-8 